\title{
Thermal Fuses for the Protection of Electric Furnaces
}

\section{HIGH TEMPERATURE PROPERTIES OF GOLD-PALLADIUM ALLOYS}

\author{
The narrow melting range of the gold-palladium alloys, together with \\ their freedom from deterioration at high temperatures, enables a \\ range of fuse elements to be provided that will melt at the rated \\ temperature and so protect both a furnace and its contents from \\ damage by overheating.
}

Electric furnaces for the heat treatment of steel components, or for sintering and brazing purposes, usually have a pre-determined maximum temperature beyond which either the furnace itself or the parts being treated could suffer damage. To avoid the risk of overheating, thermal fuses are fitted into the hot zone of the furnace and are connected directly into the control circuit. In the event of the temperature in the furnace reaching its maximum, the fuse element will melt and so cut off the power supply.

The essential requirements of a thermal fuse material are the shortest possible melting range and the maximum resistance to oxidation and corrosion. In the higher temperature range these requirements are met by gold and its range of alloys with palladium. Gold melts at $1063^{\circ} \mathrm{C}$ and obviously provides an accurate fuse if this temperature is close to the desired maximum in a particular furnace. For higher temperatures-in fact up to $1500^{\circ} \mathrm{C}$-one or other of a series of gold-palladium alloys is used. These alloys, as can be seen in the equilibrium diagram, comprise a continuous series of solid solutions with

Gold-palladium alloy thermal fuses are fitted to high temperature furnaces, both of the general purpose bateh type and the continuous belt conveyor type. Here a fitter is inserting the fuse through the roof of a hump-back mesh belt conveyor furnace being constructed by Birlec Limited for use in the heat treatment of stainless steel components in a special controlled atmosphere the solidus temperatures lying close to the liquidus points throughout. Thus in addition to freedom from deterioration during long periods at high temperatures they have a narrow melting range, and by choosing a number of points on the equilibrium diagram alloys have been made available commercially to melt at convenient intervals of $50^{\circ} \mathrm{C}$ between $1100^{\circ} \mathrm{C}$ and $1500^{\circ} \mathrm{C}$.

All the alloys in this series are ductile and can readily be drawn into wire, and these fuse elements are normally provided in the form of $1.0 \mathrm{~mm}$ diameter wire for connecting into the control circuit. Should the rated maximum temperature be reached in the event of the malfunction of an instrument, a thermocouple or a control contactor they melt

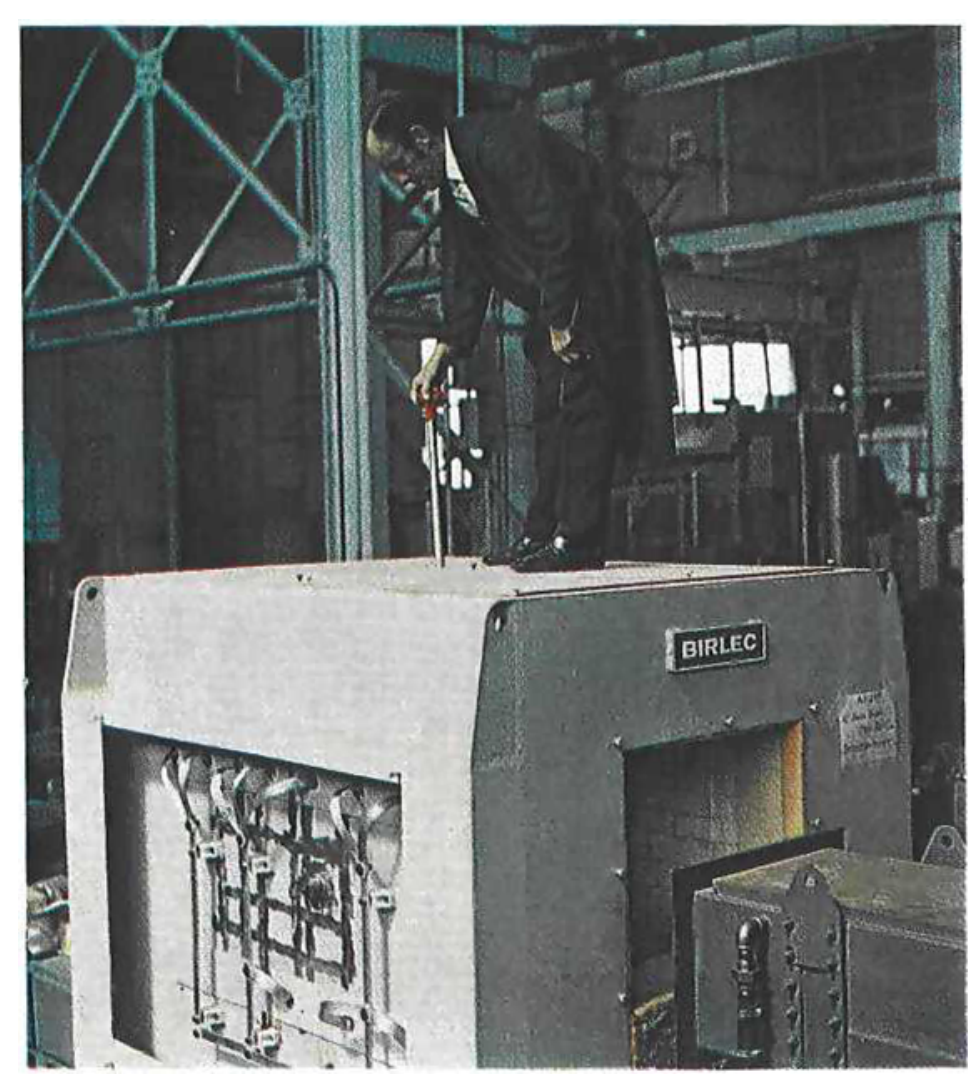


The most characteristic feature of the gold-palladium system is the close proximity of the liquidus and solidus points throughout the series of solid solutions. All the alloys thus have a very narrow melting range and thermal fuses can be provided to melt within $\pm 10^{\circ} \mathrm{C}$ of the rated temperature

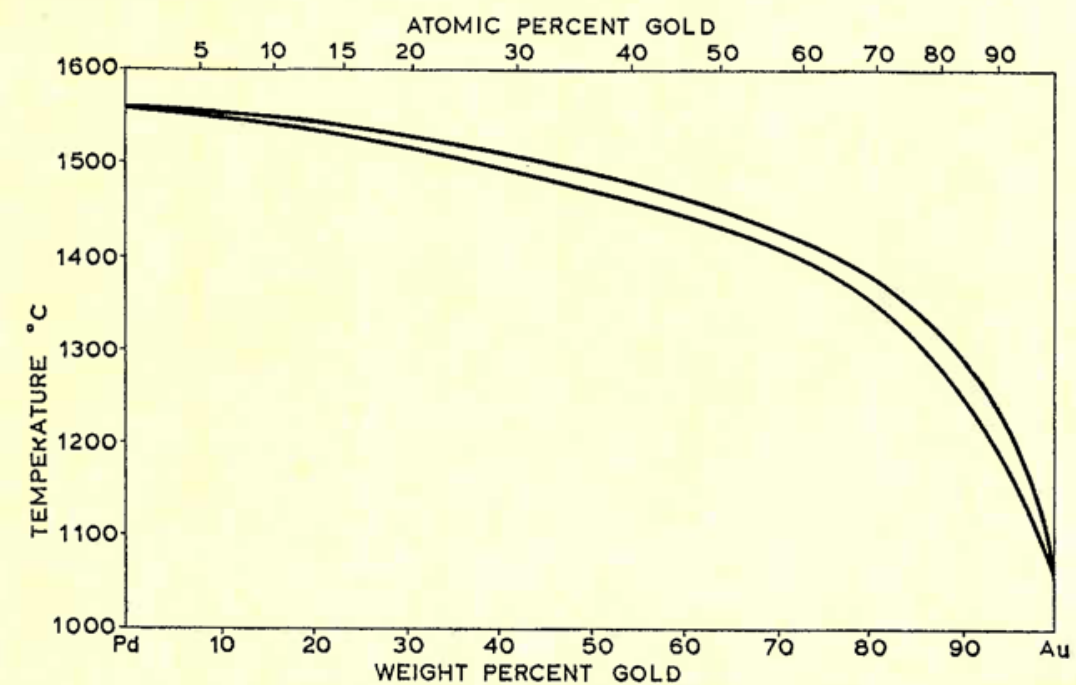

rapidly, run into beads and break the circuit, so initiating an automatic cut-off in the power supply.

The thermal fuse is thus inherently simple in operation and does not require sophisticated control equipment for its operation, nor does it involve maintenance problems or calibration. It can be connected directly into the furnace equipment control circuit, and will carry the current necessary to operate relay-type trip coils.

A few simple precautions are necessary when using thermal fuse elements. They should not be connected to nickel-chromium leads inside the hot zone of the furnace as interdiffusion and subsequent fracture are then liable to occur. If wire fuses are to be used in a vertical position it is necessary to support the weight of the electrical insulators, as otherwise the wire may be drawn out when hot, resulting in premature failure due to the reduction of diameter causing overheating, or due simply to mechanical fracture. Such support can be conveniently arranged by using three-hole insulators with a suspension wire of nickel-chromium in the third hole.

It is nearly always desirable to house the fuse in a closed-end ceramic or metal sheath; if a metal sheath is used contact between the fuse and the sheath must, of course, be avoided. As a further precaution the fuse sheath should be electrically insulated from earth, so that in the event of contact between the fuse and the sheath the leakage current does not cause failure.
The thermal fuse is housed in a ceramic or metal sheath protruding downwards into the hot zone of the furnace. By selecting a gold-palladium alloy of appropriate melting point, protection against an excessive rise in temperature is simply ensured

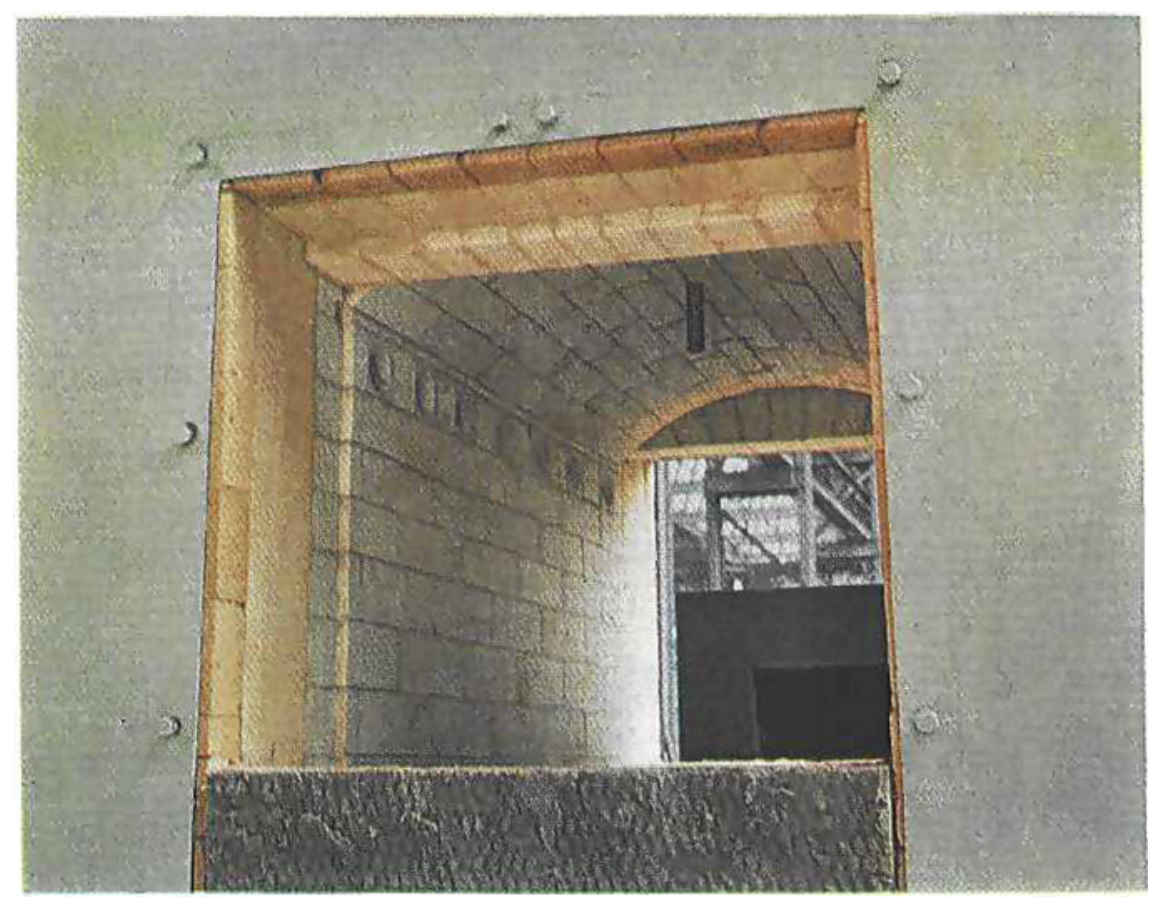

